\title{
Temperature Characteristics and Arrhenius Plots for Nominal Psychrophiles, Mesophiles and Thermophiles
}

\author{
By PHILIP W. MOHR† AND STEVEN KRAWIEC* \\ Department of Biology, Lehigh University, Bethlehem, Pennsylvania 18015, U.S.A.
}

(Received 14 May 1980)

\begin{abstract}
The specific growth rates at various temperatures of 12 bacterial species were measured and plotted as Arrhenius profiles. Temperature characteristics and optimum temperatures for maximum specific growth rates were estimated from these curves. The data reveal that one of two forms of the Arrhenius profile is characteristic of each bacterium: one curve is a simple smooth curve with a single predominant slope at sub-optimum temperatures; the other is a more complex curve with two distinct slopes at sub-optimum temperatures. The simple curve describes bacteria across the entire biokinetic range whereas the more complex curve occurs only with organisms which have optimum temperatures for replication above $37{ }^{\circ} \mathrm{C}$. Describing bacteria in terms of these forms of the Arrhenius profile is less arbitrary than is categorization based on optimum temperatures.
\end{abstract}

\section{INTRODUCTION}

A comparative examination of the rates of replication of 12 species of bacteria has revealed two distinct temperature-dependent patterns. The notable features of the investigation reported here are that: (1) the organisms selected include representatives from all the classes that have been defined on the basis of minimum, optimum and maximum temperatures for replication, namely, psychrophiles, psychrotrophs, mesophiles, stenothermophiles, eurythermophiles and extreme thermophiles (Lamanna et al., 1973); (2) all the organisms were grown in similar media, thereby minimizing a variable which is known to affect the temperature characteristic (the logarithmic proportionality between specific growth rate and the reciprocal of environmental temperature); (3) the data are presented as Arrhenius curves; and (4) analyses have been applied to the data to establish empirical relationships between optimum temperature(s) for replication and temperature characteristic(s).

The forms of Arrhenius curves for the psychrophiles, psychrotrophs, some mesophiles and some thermophiles are similar. Thus, categorizing these organisms into distinct classes by their positions in a temperature spectrum is arbitrary. Furthermore, the forms of the Arrhenius curves for some mesophiles and some thermophiles are more complex than those for the psychrophiles and other mesophiles and thermophiles. The two recurrent forms of the Arrhenius curve establish uncontrived categories which can be used to classify the temperature-dependent rates of replication of bacteria.

\section{METHODS}

Source of organisms. Vibrio psychroerythris ATCC 27364, V. marinus ATCC 15381 and $V$. marinus ATCC 15382 were obtained from the American Type Culture Collection: $V$. marinus has been listed as $V$. fischeri in the twelfth edition of the ATCC catalogue, but the strain numbers have been retained. Thermus

$\dagger$ Present address: Department of Microbiology, Cell Biology, Biochemistry and Biophysics, The Pennsylvania State University, University Park, Pennsylvania 16802, U.S.A. 
aquaticus strain TY was provided by Professor T. D. Brock, University of Wisconsin (Madison), U.S.A. Pseudomonas fluorescens, P. aeruginosa, Serratia marcescens, Escherichia coli, Bacillus subtilis, B. megaterium, $B$. coagulans and $B$. stearothermophilus were taken from stocks maintained at Lehigh University.

Media. All organisms except $V$. psychroerythrus were maintained and grown on the basal salts medium described by Brock \& Freeze (1969). For the $V$. marinus strains, $\mathrm{NaCl}$ was added to a final concentration of $3.5 \%(\mathrm{w} / \mathrm{v})$. Vibrio psychroerythrus was grown in medium containing $0.5 \mathrm{M} \cdot \mathrm{NaCl}, 0.3 \mathrm{M}-\mathrm{MgCl}_{2}, 0.4 \mathrm{mM}^{-}$ $\mathrm{KH}_{2} \mathrm{PO}_{4}, 0.01 \mu \mathrm{M}-\mathrm{FeCl}_{2}, 0.15 \mathrm{mM} \cdot \mathrm{CaCl}_{2}$ and $0.8 \%(\mathrm{w} / \mathrm{v})$ tryptone; $\mathrm{pH} 7 \cdot 0$ (D'Aoust \& Kushner, 1971 ).

Growth. Growth was monitored spectrophotometrically at $660 \mathrm{~nm}$ (Bausch and Lomb, Spectronic 20). Erlenmeyer flasks $(300 \mathrm{ml})$ with cuvettes fused to the sides and containing $25 \mathrm{ml}$ of the appropriate medium were inoculated from an overnight culture or, in the case of psychrophiles, a 48 to $72 \mathrm{~h}$ culture. The initial turbidity was generally between 0.02 and 0.05 . The cultures were incubated in a rotary water-bath shaker (New Brunswick, model G76) operating at $180 \mathrm{rev}$. min $^{-1}$. Temperatures were maintained within $\pm 0.5^{\circ} \mathrm{C}$. For temperatures below ambient, a low temperature circulator was connected to the water-bath shaker. Turbidity was measured at 15,30 or 60 min intervals and plotted against time. Regression analyses were performed for the exponential phase of growth.

Arrhenius plots were constructed by plotting $\log _{\mathrm{e}}\left(10^{3} \times k\right)$ against $10^{3} \times 1 / T$, where $k$ is the specific growth rate $\left(\mathrm{h}^{-1}\right)$ and $T$ is the absolute temperature $(\mathrm{K})$. The specific growth rates at each temperature were calculated from at least two giowth curves or, more typically, from three to six growth curves. Temperature characteristics were determined from the slopes of the linear portion of the Arrhenius curves at sub-optimum temperatures. In those instances in which there were two distinct slopes at sub-optimum temperatures, the data points were grouped to produce the highest sum of $r^{2}$ values for the two lines.

\section{RESULTS AND DISCUSSION}

A modified version of the Arrhenius equation

$$
k=\mathrm{Ae}^{-\mu / R T}
$$

in which $\mu$, a temperature characteristic, is substituted for $E_{\mathrm{a}}$, an activation energy, describes the specific growth rate, $k$, of bacteria over a limited temperature range (cf. Ingraham, 1962). Unlike enzymic reactions, bacterial cells are holistic systems which need not be viewed as a catenary sequence of reactions controlled by one or more master reactions. Furthermore, they are not dilute, homogeneous, nor wholly aqueous. Nonetheless, equation 1 is an accurate statement of the temperature-dependence of the specific growth rate over a large range of sub-optimum temperatures.

The specific rate of replication at any temperature (between the maximum for growth, $T_{\max }$, and the minimum, $T_{\min }$ ) can be described as the overall temperature-dependent rate(s) of synthesis minus the overall temperature-dependent rate of degradation (Allen, 1953; Dean \& Hinshelwood, 1966). For example,

$$
k=\mathrm{A}_{1} \mathrm{e}^{-\mu_{1} / R T}-\mathrm{A}_{2} \mathrm{e}^{-\mu_{2} / R T}
$$

is a formulation which provides an accurate statement of specific growth rates at most temperatures for many bacteria. Unfortunately, a manner in which the values of $A_{1}, A_{2}$, $\mu_{1}$ and $\mu_{2}$ (in equation 2) can be readily and accurately obtained has not been established (Dean \& Hinshelwood, 1966). But, $\mu_{1}$ can be estimated from the negative slopes in the Arrhenius profiles and $\mu_{2}$ from the positive ones.

The Arrhenius plots for $V$. psychroerythrus and the two $V$. marinus strains (nominally psychrophiles) are presented in Fig. 1 ; those for $S$. marcescens, $P$. fluorescens, $E$. coli, $B$. subtilis, $B$. megaterium and $P$. aeruginosa (nominally mesophiles) in Fig. 2 ; and those for $B$. stearothermophilus, B. coagulans and $T$. aquaticus (thermophiles) in Fig. 3. Optimum temperatures were determined by inspection for maximum growth rates on Arrhenius plots. Values for $\mu$ were calculated by regression analyses for the one or two linear portions of the curve that occur below the optimum temperature. The optimum temperatures and the temperature characteristics for the 12 organisms are summarized in Table 1.

The Arrhenius profiles for $V$. psychroerythrus, $V$. marinus, $S$. marcescens, $P$. fluorescens and $T$. aquaticus (Figs 1, 2 and 3) can be described by equation 2 . Thus, this pattern of temperature-dependent growth occurs over the entire biokinetic range. 


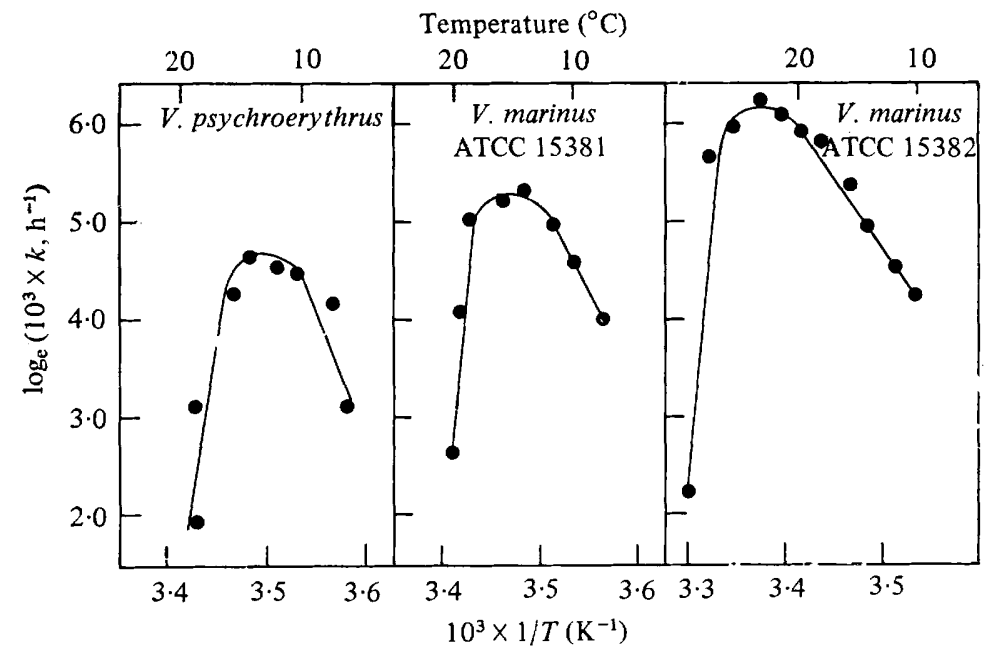

Fig. 1. Arrhenius curves for $V$. psychroerythrus, $V$. marinus 15381 and $V$. marinus 15382. The $r^{2}$ values for the slopes from which $\mu_{1}$ values were calculated were 0.93 for $V$. psychroerythrus, 0.99 for $V$. marinus 15381 , and 0.98 for $V$. marinus 15382 .

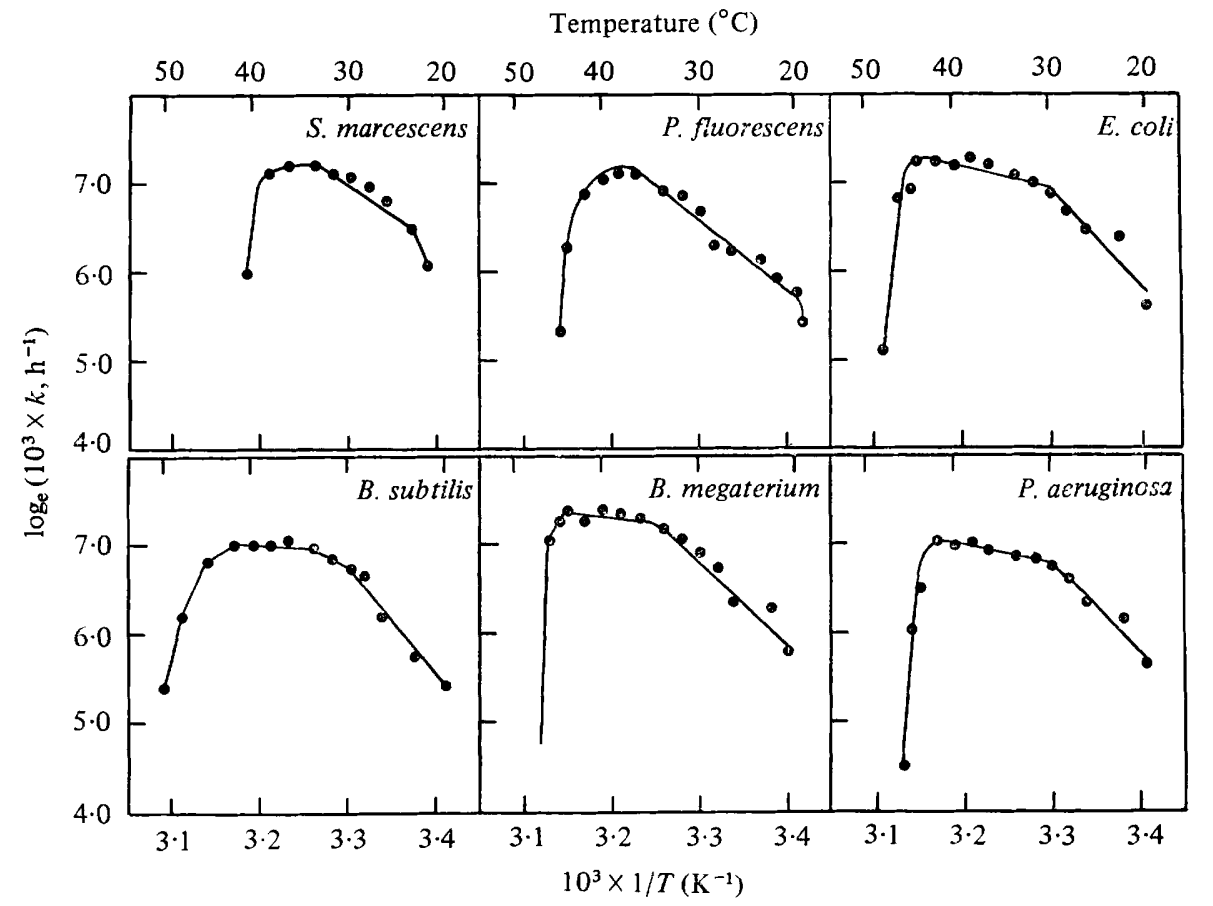

Fig. 2. Arrhenius curves for $S$. marcescens, $P$. fuorescens, E. coli, B. subtilis, B. megaterium and $P$. aeruginosa. The $r^{2}$ values for the slopes from which $\mu_{1}$ values were calculated were 0.96 for $S$. marcescens and 0.98 for $P$. fluorescens. The $r^{2}$ values for the slopes from which the $\mu_{1}$ and $\mu_{1}^{\prime}$ values were calculated were, respectively, 0.32 and 0.99 for $B$. subtilis, 0.56 and 0.97 for $B$. megaterium, 0.95 and 0.96 for $P$. aeruginosa, and 0.85 and 0.87 for $E$. coli. 


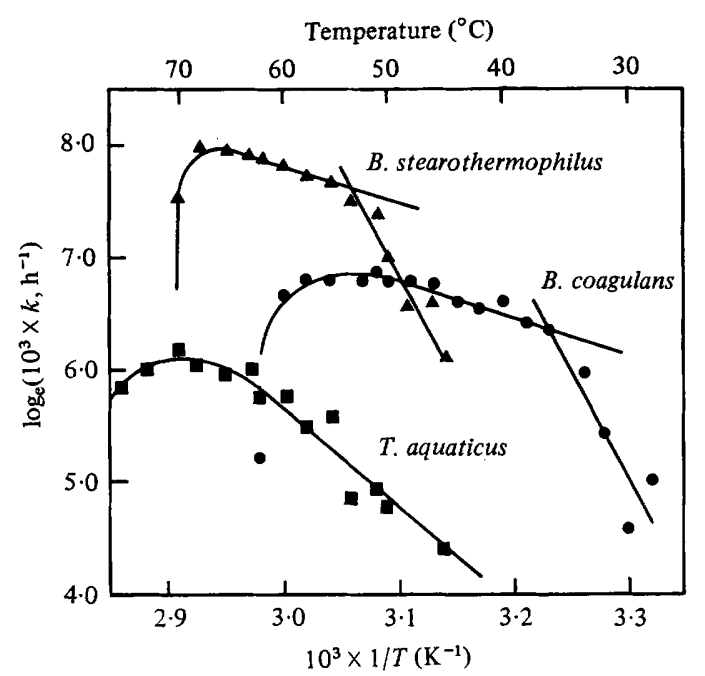

Fig. 3. Arrhenius curves for T. aquaticus ( $\mathbf{\square}), \boldsymbol{B}$. coagulans $(\mathbf{O})$ and $\boldsymbol{B}$. stearothermophilus (A). The $r^{2}$ value for the slope from which $\mu_{1}$ of T. aquaticus was calculated was 0.95 . The $r^{2}$ values for the slopes from which the $\mu_{1}$ and $\mu_{1}^{\prime}$ values were calculated were, respectively, 0.97 and 0.92 for $B$. stearothermophilus and 0.93 and 0.88 for B. coagulans.

Table 1. Optimum temperature for growth and temperature characteristics of selected prokaryotes

\begin{tabular}{lccc}
\multicolumn{1}{c}{ Organism } & $\begin{array}{c}\text { Optimum } \\
\text { temperature } \\
\left({ }^{\circ} \mathrm{C}\right)\end{array}$ & $\mu_{1}$ (cal) $\dagger$ & $\mu_{1}^{\prime}$ (cal) \\
Vibrio psychroerythrus & $13 \cdot 8$ & 51900 & \\
V. marinus ATCC 15381 & $15 \cdot 5$ & 39000 & \\
V. marinus ATCC 15382 & $24 \cdot 0$ & 23200 & \\
Serratia marcescens & $34 \cdot 5$ & 12700 & \\
Pseudomonas fluorescens & $37 \cdot 9$ & 15500 & 24700 \\
Bacillus subtilis & $38 \cdot 1$ & 900 & 17800 \\
B. megaterium & $39 \cdot 6$ & 2400 & 18400 \\
Pseudomonas aeruginosa & $42 \cdot 3$ & 3700 & 30300 \\
Escherichia coli & $44 \cdot 5$ & 4400 & 30100 \\
Bacillus coagulans & $53 \cdot 9$ & 6500 & \\
B. stearothermophilus & $65 \cdot 8$ & 6600 & \\
Thermus aquaticus & $70 \cdot 2$ & 17800 &
\end{tabular}

* The $r^{2}$ values for the slopes from which $\mu_{1}$ values were calculated were significant at the level of 0.995 for $V$. marinus $15382, S$. marcescens, $P$. fuorescens, $P$. aeruginosa, E. coli, B. coagulans, B. stearothermophilus and $T$. aquaticus, and at the level of 0.95 for $V$. marinus 15381 ; the values for V.psychroerythrus, B. subtilis and $B$. megaterium are significant at lower levels. The $r^{2}$ values for the slopes from which $\mu_{1}^{\prime}$ values were calculated were significant at the level of 0.995 for B. subtilis, B. megaterium, $P$. aeruginosa, B. coagulans and $B$. stearothermophilus, and at the level of 0.95 for $E$. coli.

$\dagger 1 \mathrm{cal}=4 \cdot 184 \mathrm{~J}$.

The Arrhenius profiles for some mesophiles and thermophiles have two slopes at suboptimum temperatures (Figs 2 and 3). The point which is common to both slopes has been called the 'critical temperature', $T_{\text {crit }}$ (Lamanna et al., 1973). Equations 1 and 2 can be combined to describe the more complex pattern of growth. One combination is

$$
\begin{aligned}
k & =\mathrm{A}_{1} \mathrm{e}^{-\mu_{2} / R T}-\mathrm{A}_{2} \mathrm{e}^{-\mu_{2} / R T} & T_{\text {crit }} & <T<T_{\max } \\
& =\mathrm{A}_{1}{ }^{\prime} \mathrm{e}^{-\mu_{1} / R T} & T_{\min } & <T<T_{\text {crit }}
\end{aligned}
$$


in which $\mu_{1}^{\prime}$ is the temperature characteristic for growth between $T_{\text {crit }}$ and $T_{\min }$, and $\mu_{1}$ is the temperature characteristic for growth between $T_{\text {crit }}$ and the optimum temperature. These relationships imply that the organism undergoes a discrete change in organization at $T_{\text {crit }}$, that is, equation 3 describes temperature-dependent growth at temperatures greater than $T_{\text {crit }}$ and equation 4 describes temperature-dependent growth below $T_{\text {erit }}$. A contrasting description is that a balance of organizations exists at any temperature. This condition can be shown as

$$
k=\frac{\mathrm{A}_{1} \mathrm{e}^{-\mu_{1} / R T} \cdot \mathrm{A}_{1}{ }^{\prime} \mathrm{e}^{-\mu_{1}^{\prime} / R T}}{\mathrm{~A}_{1} \mathrm{e}^{-\mu_{1} / R T}+\mathrm{A}_{1}{ }^{\prime} \mathrm{e}^{-\mu_{1}^{\prime} / R T}}-\mathrm{A}_{2} \mathrm{e}^{-\mu_{2} / R T}
$$

Equation 5 can be reduced to

$$
k=\frac{1}{\mathrm{~A}_{1}{ }^{*} \mathrm{e}^{\mu_{1}^{\prime} / R T}+\mathrm{A}_{1}{ }^{*} \mathrm{e}^{\mu_{1} / R T}}-\mathrm{A}_{2} \mathrm{e}^{-\mu_{2} / R T}
$$

in which $A_{1}{ }^{*}=1 / A_{1}{ }^{\prime}$ and $A_{1}{ }^{* *}=1 / A_{1}$.

Inspection of the Arrhenius profiles for E. coli, B. subtilis, B. megaterium and P. aeruginosa reveals that these organisms have Arrhenius profiles with two discrete slopes at suboptimum temperatures (Fig. 2). This form of the profile is more pronounced with some thermophiles - in particular, with $B$. coagulans and B. stearothermophilus (Fig. 3). Our data show that the more complex curves describe the growth of both Gram-negative and Grampositive organisms. Complex curves occur exclusively but not necessarily with organisms having optimum temperatures above $37^{\circ} \mathrm{C}$.

The disparate Arrhenius profiles and the differences between equation 2 and equations 3 and 4 , or between equation 2 and equation 6 , indicate that different patterns of temperaturedependent growth occur. These formulations might exclude some proposed mechanisms of temperature-dependent growth but they cannot specify the actual mechanisms. That several organizational states exist among the thermophiles is shown by the various positions of Arrhenius curves in the field established by the temperature and growth rate coordinates. Organisms with similar optimum temperatures, e.g. B. stearothermophilus and T. aquaticus, differ in their temperature characteristics and markedly so in their maximum rates of replication.

Generally speaking, there appears to be good agreement among corrected values of $\mu_{1}$ calculated in different laboratories despite differences in strains, media and some physical growth conditions. Hanus \& Morita (1968) report $\mu$ values for $V$. marinus isolates using the base 10 while our values employ the base e. Close agreement becomes apparent when their values are multiplied by $2 \cdot 303$ to correct for this difference. Similarly, Ingraham (1958) reported a temperature characteristic for $E$. coli, the calculation of which omitted the gas factor (cf. Hanus \& Morita, 1968). Multiplying his value by 1.987 to correct for the omission leads to good agreement with the value we report. Ward \& Cockson (1972) calculated a temperature characteristic of 26400 cal for a Gram-positive, endospore-forming rod which appears to be a strain of $B$. stearothermophilus. Their value is based on growth rates at four sub-optimum temperatures and is one that falls between the two temperature characteristics we obtained by measuring growth rates at 12 sub-optimum temperatures. The $17000 \mathrm{cal}$ temperature characteristic observed for Myxococcus xanthus, which has an optimum temperature for replication of 34 to $36^{\circ} \mathrm{C}$, is similar in magnitude to the value we observed for bacteria with optimum temperatures in this range (Janssen et al., 1977). Also, the temperature characteristics of 15000 and $13500 \mathrm{cal}$ in minimal and rich media, respectively, for an unidentified bacillus (Epstein \& Grossowicz, 1969) with an optimum temperature from 55 to $58{ }^{\circ} \mathrm{C}$ is consistent with our observations (see below).

In this study, estimates of the temperature characteristics for organisms with optimum temperatures across a major portion of the biokinetic range were obtained These data allow formulation of empirical relationships between the optimum temperatures for replication 


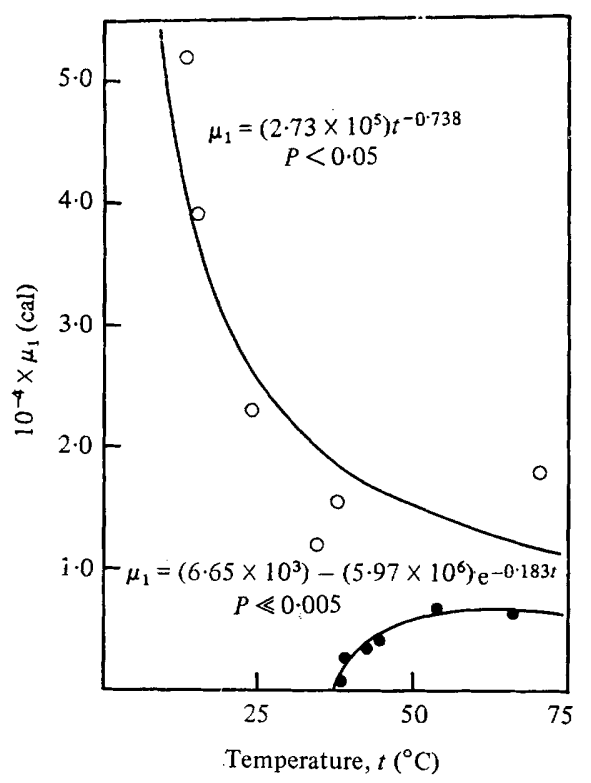

Fig. 4. Empirical relations between $\mu_{1}$ values and the optimum temperatures for growth: $\bigcirc, \mu_{1}$ values for organisms which have a single predominant slope in their Arrhenius profiles at suboptimum temperatures; $\bigcirc \mu_{1}$ values for organisms with two distinct slopes in their Arrhenius profiles at sub-optimum temperatures.

and temperature characteristics. Figure 4 presents all $\mu_{1}$ values which we have estimated. It may be statistically improper to include in a single regression $\mu_{1}$ values from organisms with different forms of the Arrhenius profile, i.e. from organisms with two distinct slopes at suboptimum temperatures as opposed to those with a single slope. Accordingly, two curves have been drawn; the upper line (O) relates the optimum temperature $\left(t,{ }^{\circ} \mathrm{C}\right)$ and $\mu_{1}$ values (cal) for those organisms described by equation 2 ; the lower line (O) relates the optimum temperature and $\mu_{1}$ values for those organisms described by equations 3 and 4 , or equation 6. The upper curve of Fig. 4 is best described (Crowe \& Crowe, 1969) by the empirical equation:

$$
\mu_{1}=\left(2 \cdot 73 \times 10^{5}\right) t^{-0} 738
$$

The lower curve best fits the empirical equation (Crowe \& Crowe, 1969):

$$
\mu_{1}=\left(6.65 \times 10^{3}\right)-\left(5.97 \times 10^{6}\right) \mathrm{e}^{-0.183 t}
$$

At $37.2^{\circ} \mathrm{C}$, the $\mu_{1}$ value becomes zero indicating that only organisms with an optimum temperature of approximately this value or greater can have two distinct temperature characteristics at sub-optimum temperatures.

The observations presented in this report indicate that the temperature-dependent specific growth rates of selected bacteria occur in two patterns. Each of these patterns can be expressed as a variation of the Arrhenius equation. Furthermore, for each pattern of growth, the temperature characteristics (which describe the rate of change of specific growth rate in a range of temperatures just below the optimum) vary in a regular but non-linear manner relative to optimum temperature.

We wish to thank Margaret Krawiec and Drs Barry Bean, Brent Benson, Edwin Kay and Jeffrey Sands for their constructive criticisms of this report. Some of these observations and interpretations were submitted by P. W. Mohr to the Graduate Committee of Lehigh 
University as partial fulfilment of the requirements for the degree of Doctor of Philosophy. Financial support of this investigation was provided by grants from the Society of the Sigma Xi and the National Institute of General Medical Sciences (GM19856).

\section{REFERENCES}

Allen, M. B. (1953). The thermophilic aerobic sporeforming bacteria. Bacteriological Reviews 17, $125-173$.

Brock, T. D. \& Freeze, H. (1969). Thermus aquaticus gen.n. and sp.n., a non-sporulating extreme thermophile. Journal of Bacteriology 98, 289-297.

Crowe, A. \& Crowe, A. (1969). Mathematics for Biologists. New York: Academic Press.

D'Aoust, J. Y. \& KushneR, D. J. (1971). Structural changes during lysis of a psychrophilic marine bacterium. Journal of Bacteriology 108, 916-927.

DeAN, A. C. R. \& Hinshelwood, C. (1966). Growth, Function and Regulation in Bacterial Cells. London: Oxford University Press.

Epstein, I. \& Grossowicz, N. (1969). Prototrophic thermophilic Bacillus: isolation, properties, and kinetics of growth. Journal of Bacteriology 99, 414-417.

Hanus, F. J. \& Morita, R. Y. (1968). Significance of the temperature characteristic of growth. Journal of Bacteriology 95, 736-737.

INGRAHAM, J. L. (1958). Growth of psychrophilic bacteria. Journal of Bacteriology 76, 75-80.

INGRAHAM, J. L. (1962). Temperature relationships. In The Bacteria, vol. 4, pp. 265-296. Edited by I. C. Gunsalus \& R.Y.Stanier. New York: Academic Press.

Janssen, G. R., Wireman, J. W. \& Dworkin, M. (1977). Effect of temperature on the growth of Myxococcus xanthus. Journal of Bacteriology 130, 561-562.

Lamanna, C., Mallette, M. F. \& Zimmerman, L. N. (1973). Basic Bacteriology, 4th edn. Baltimore: Williams \& Wilkins.

WARD, J. \& Cockson, A. (1972). Studies on a thermophilic bacillus: its isolation, properties, and temperature coefficient of growth. Journal of Bacteriology 112, 1040-1042. 